\title{
Care transition of patients with chronic diseases from the discharge of the emergency service to their homes
}

\author{
Transição do cuidado de pacientes com doenças crônicas \\ na alta da emergência para o domicílio \\ Transición del cuidado de pacientes con enfermedades crónicas \\ desde el alta del servicio de emergencia hasta el domicilio

\section{Aline Marques Acosta Maria Alice Dias da Silva Lima ${ }^{a}$ lone Carvalho Pinto ${ }^{b}$ Luciana Andressa Feil Weberc}

How to cite this article: Acosta AM, Lima MADS, Pinto IC, Weber LAF. Care transition of patients with chronic diseases from the discharge of the emergency service to their homes. Rev Gaúcha Enferm. 2020;41(esp):e20190155. doi: https://doi.org/10.1590/19831447.2020.20190155 aniversidade Federal do Rio Grande do Sul (UFRGS), Escola de Enfermagem, Departamento de Assistência e Orientação Profissional. Porto Alegre, Rio Grande do Sul, Brasil.

- Universidade de São Paulo (USP), Escola de Enfermagem de Ribeirão Preto, Departamento de Enfermagem Materno-Infantil e Saúde Pública. Ribeirão Preto, São Paulo, Brasil.

c Universidade Federal do Rio Grande do Sul (UFRGS), Escola de Enfermagem, Programa de Pós-Graduação em Enfermagem. Porto Alegre, Rio Grande do Sul, Brasil.

\section{ABSTRACT}

Objective: To evaluate the quality of the care transition for patients with chronic non-communicable diseases discharged from the emergency department to home.

Method: A cross-sectional observational and epidemiological study conducted at an emergency department in the South of Brazil with 117 patients and 81 caregivers. The Care Transitions Measure was applied by phone to collect data. A descriptive and analytical statistical analysis was performed.

Results: The quality of the care transition's total score was close to satisfactory (69.5). The "Self-Management Training" factor had the highest score (70.6), while "Understanding medications" had the lowest (68.3). Items related to understanding medications and confidence in carrying out care after discharge obtained lower scores.

Conclusions: A moderate quality of the care transition was evidenced, as well as the need to adopt strategies to improve the emergency department discharge process and the continuity of the care of patients with chronic diseases.

Keywords: Patient discharge. Continuity of patient care. Chronic disease. Non-communicable diseases. Emergency nursing.

\section{RESUMO}

Objetivo: Avaliar a qualidade da transição do cuidado de pacientes com doenças crônicas não transmissíveis na alta do serviço de emergência para o domicílio.

Método: Estudo epidemiológico observacional transversal realizado em serviço de emergência de hospital no Sul do Brasil com 117 pacientes e 81 cuidadores. Na coleta de dados, aplicou-se por telefone o instrumento Care Transitions Measure. Realizou-se análise estatística descritiva e analítica.

Resultados: 0 escore total da qualidade da transição do cuidado foi próximo ao satisfatório (69,5). 0 fator "Preparação para autogerenciamento" teve maior escore $(70,6)$, enquanto "Entendimento sobre medicações", o menor $(68,3)$. Escores inferiores foram obtidos nos itens relacionados a conhecimento sobre medicamentos e segurança em realizar os cuidados após a alta.

Conclusões: Evidenciou-se qualidade moderada da transição do cuidado e necessidade de adoção de estratégias para melhorar 0 processo de alta da emergência e a continuidade do cuidado de portadores de doenças crônicas.

Palavras-chave: Alta do paciente. Continuidade da assistência ao paciente. Doença crônica. Doenças não transmissíveis. Enfermagem em emergência.

\section{RESUMEN}

Objetivo: Evaluar la calidad de la transición de los cuidados de pacientes con enfermedades crónicas no transmisibles desde el alta del servicio de emergencia hasta el domicilio.

Método: Estudio epidemiológico, observacional y transversal realizado en un servicio hospitalario de emergencia en el sur de Brasil con 117 pacientes y 81 cuidadores. En la recolección de los datos, se aplicó telefónicamente el instrumento Care Transitions Measure. Se realizó un análisis estadístico, descriptivo y analíico.

Resultados: El puntaje total de la calidad de la transición de los cuidados fue cercano a satisfactorio $(69,5)$. El factor"Preparación para el automanejo" obtuvo el mayor puntaje (70,6), mientras que "Entender los medicamentos" obtuvo el menor (68,3). Se obtuvieron puntajes más bajos en los ítems relacionados con el conocimiento sobre los medicamentos y la seguridad en realizar los cuidados después del alta.

Conclusiones: Se evidenció una calidad moderada de la transición de los cuidados y la necesidad de adoptar estrategias para mejorar el proceso del alta del servicio de emergencia y la continuidad de los cuidados de portadores de enfermedades crónicas.

Palabras clave: Alta del paciente. Continuidad de la atención al paciente. Enfermedad crónica. Enfermedades no transmisibles. Enfermería de urgencia. 


\section{口INTRODUCTION}

Continuity of care is a challenge for health care systems worldwide, as more and more patients are seen by different professionals in the several care network services, requiring care integration and connectivity over time ${ }^{(1)}$. It is known that patients may be more susceptible to fragmented care when transitioning between different health services.

Fragmentation of care is especially worrisome for people with chronic non-communicable diseases (CNCDs). These diseases, mainly represented by cardiovascular and chronic respiratory diseases, cancer and diabetes, are the main causes of morbidity and mortality and a problem of great magnitude, both nationally and internationally ${ }^{(2)}$.

Patients with CNCDs require continuity of care from several professionals in multiple services for disease control and prevention, but eventually the disease becomes more acute and exacerbated, requiring urgent care. Evidence indicates that these individuals, besides representing a greater number of hospitalizations ${ }^{(2)}$, are also more likely to visit emergency departments ${ }^{(3)}$. Punctual and fragmented care provided by emergency services, however, may be insufficient to address the patients'health needs because, when there is no continuity of care, exacerbations and use of emergency departments can become more frequent events in a cyclical process ${ }^{(4)}$.

Discharge from the emergency department is considered an especially critical period for the patient, as these services have singularities that include a high demand for care, overcrowding, overload on health care teams, high turnover and pressure for bed release. Failure to prepare for self-management at home often occurs, with hasty discharge education and patients poorly understanding their health situation and post-discharge care ${ }^{(5-6)}$. Furthermore, there are weakness in the articulation of emergency department with other services of the health care network, which are evidenced mainly by the lack of counter-referral to primary and specialized care and by the scheduling of returns to the emergency department for a reevaluation of the health condition ${ }^{(4)}$. It is estimated that four out of ten patients treated and discharged from emergency care have problems with self-management after discharge and about 15\% return to the service within two weeks ${ }^{(6)}$.

In spite of that, it is considered that emergency departments play a fundamental role in linking and articulating the health care network, while the discharge process could be a privileged moment to stimulate the integration of health care services, reducing the frequent demand for emergency care ${ }^{(4)}$. Thus, care transition is considered an important strategy to ensure continuity of care and patient safety ${ }^{(3)}$, especially for people with chronic diseases who need continuous and persistent care ${ }^{(7-8)}$.
Care transitions often include actions of discharge planning, patient and family health education, articulation between the health services, communication between teams and post-discharge follow-up ${ }^{(3,8)}$, with nurses being the main professionals responsible for the coordination of care $e^{(9)}$. These strategies have demonstrated a positive impact on the quality of life of patients and their families, as well as on reducing hospital readmissions, on the search for emergency departments and on health care costs $s^{(3,7)}$.

International studies have been developed to improve the transition of hospitalized patients in inpatient units ${ }^{(10-11)}$. However, there are few publications evaluating the quality of the transition of people with CNCDs upon discharge from emergency departments ${ }^{(6)}$. It is understood that the perspective of the patients and their families on care transition is important for nurses and managers to develop evidence-based transition strategies and practices, contributing to greater patient safety, and improving continuity of care and quality of health care.

Given the above, this study aimed to evaluate the quality of the transition of patients with chronic non-communicable diseases discharged from the emergency department to home.

\section{METHOD}

This paper, extracted from a doctoral dissertation ${ }^{(12)}$, is characterized as an observational and cross-sectional epidemiological study conducted in an emergency department of a large university hospital in the South of Brazil. The hospital has 839 beds and the emergency service has 41 beds for adults. The emergency department has an average public ranging from 130 to 150 patients a day and an occupancy rate ranging from $91.87 \%$ to $392.91 \%$ due to overcrowding.

The study population consisted of adult patients with chronic diseases who were discharged from the emergency department to their homes. The following were considered as CNCDs: cancer, diabetes, and chronic cardiac, neurological, respiratory, kidney and musculoskeletal diseases ${ }^{(12)}$. The study population was identified from weekly reports of the computerized hospital management system. For the sample calculation, a 5\% margin of error, a 95\% confidence level and an estimate of 50 patients with CNCDs a day in the service were used, establishing a random sample of 198 participants $(n=198)$.

The inclusion criteria were the following: being 18 years old or older, having one or more CNCDs, remaining in the emergency department for at least 24 hours (minimum period to characterize hospitalization according to institutional norms) and being discharged home. Patients 
who were hospitalized at the time of data collection or died after discharge were excluded. During data collection, if the patient had a cognitive or communication deficit that prevented them from answering the survey, the caregiver who assisted them in both hospitalization and discharge from the service was interviewed as a substitute respondent (proxy informant) $)^{(13)}$. Caregivers present only in hospitalization or only at discharge were excluded. 14 patients refused to participate in the study and 52 were not found after three attempts, being replaced. Thus, 117 patients and 81 caregivers answered the survey, totaling 198 participants.

The first part of the data collection was performed between April and July 2015, through phone calls made by the researchers within one to four weeks after the participant's discharge. A form with patient data was used and completed with information present in the weekly report. The following variables were collected: gender, age, schooling, morbidity, risk rating, care room, length of stay, shift and day of discharge and number of previous visits to the service.

Care Transitions Measure (CTM-15)(13) adapted for use in Brazil was also used. This instrument was created in the United States from focus groups with patients and their caregivers to assess the quality and experience of care transition in aspects related to information transfer, instructions to the patient and caregiver, self-management support, and assurance of patient and caregiver preferences in the care plan ${ }^{(14)}$. The Brazilian version has semantic equivalence with the original, good applicability and easy comprehension, apart from a satisfactory face and content validity, satisfactory internal consistency and temporal stability, showing good psychometric properties ${ }^{(13)}$. It consists of 15 items, organized into four factors, namely: Management Preparation; Understanding Medications; Preferences Imported, and Care Plan. The instrument is often applied by telephone contact and allows the caregiver to respond as a proxy when the patient is in a very poor health condition. The answer options are arranged on a five-point Likert scale.

The second part of the data collection took place in November 2015, when the participants' medical records showed readmission to the emergency department and/ or hospital admission three months after the emergency discharge.

The collected data was registered in Excel and the analysis was performed through the Statistical Package for the Social Sciences (SPSS) program, version 21.0. Descriptive statistics was used, presenting absolute and percentage frequency data for categorical variables and calculating position and dispersion measures for continuous variables. A score based on the participant's answer was assigned to each item of the instrument, as follows: Don't Know/Don't Remember/
Not Applicable $=0 ;$ Strongly Disagree $=1$ point; Disagree $=2$ points; Agree $=3$ points; Strongly Agree $=4$ points. A simple average answer for each item was obtained, as well as the average of the total scale and per factor according to the validation factor analysis of the $\mathrm{CTM}^{(13)}$. As instructed by the authors of the instrument ${ }^{(14)}$, a formula was used that transforms the averages obtained into scores from 0 to 100 . It is considered that the higher the score obtained, the better the care transition. Although there is no cut-off point, the authors consider that a score equal to or greater than 70 is satisfactory.

Subsequently, inferential statistics were performed to verify associations and correlations between the quality of care transition (dependent variable) and the other independent variables. Student's t-test, analysis of variance (ANOVA), Pearson's correlation test, nonparametric Spearman's correlation and Cronbach's alpha were used, with a significance level of $5 \%(p \leq 0.05)$.

The research was approved by the Research Ethics Committee of the institution (CAAE No. 40208114.7.0000.5327 and opinion No.937,211), following the ethical principles that govern research with human beings. Consent to participate in the research was implied and the verbal consent of the participant was obtained at the time of the phone call, using a telephone script with information regarding the objective, justification, purpose, risks and benefits of the research, guarantee of voluntariness and anonymity.

\section{口 RESULTS}

In this study, there were more female patients (53\%), with a mean age of 62.4 years old $( \pm 15.3)$ and incomplete elementary education (52.2\%). The most prevalent chronic diseases were cardiovascular diseases (57.6\%), followed by cancer (27.3\%) and diabetes (18.7\%). Regarding length of stay, a median of two days was identified (interquartile range from 1 to 3). The day of the week patients were most frequently discharged from the emergency department was Friday (24.7\%), in the afternoon shift (59.1\%). $16.7 \%$ of the patients had four or more previous visits to the service in one year. In addition, $38.9 \%$ of the patients were readmitted to the emergency department, $15.6 \%$ within one month after discharge and 23.2\% within three months. Almost 18\% were hospitalized after discharge.

Regarding the CTM-15 results, the total score ranged from 26.67 to 100 , with a mean of 69.5 and a Cronbach's alpha coefficient of 0.922 . The mean scores according to the factors were similar, although factor 1 (Management Preparation) had the highest mean value and factor 2 (Understanding Medications) and the lowest (Table 1). 
Table 2 presents the mean and standard deviation obtained for each item of the instrument. The items with the highest scores were items 14 (included in the "Understanding Medications"factor), 9 and 5 (included in the "Management
Preparation"factor). Items 15, 11 and 3 had the lowest mean values and were included in the "Understanding Medications", "Management Preparation" and "Preferences Imported" factors, respectively.

Table 1 - Distribution of the mean values and standard deviation of the total CTM-15 score and per factor. Porto Alegre, RS, Brazil, 2015

\begin{tabular}{lcc} 
CTM-15* Score & \multicolumn{1}{c}{$\begin{array}{c}\text { Mean } \pm \\
\text { Cronbach's } \\
\text { Alpha }\end{array}$} \\
Total & $69.5 \pm 19.7$ & 0.922 \\
\hline Per factor & & 0.918 \\
\hline Factor 1 -Management Preparation & $70.6 \pm 23.3$ & 0.647 \\
\hline Factor 2 - Understanding Medications & $68.3 \pm 22.5$ & 0.787 \\
\hline Factor 3 - Preferences Imported & $68.4 \pm 22.7$ & 0.641 \\
\hline Factor 4 - Care Plan & $68.8 \pm 26.9$ & 0.97 \\
\hline
\end{tabular}

Source: Research data, 2015.

Table 2 - Distribution of the mean values and standard deviation per CTM-15 item. Porto Alegre, RS, Brazil, 2015

\begin{tabular}{|c|c|c|c|}
\hline Item No. & Factor & CTM-15* & $\begin{array}{l}\text { Mean } \pm \\
\text { Standard Deviation }\end{array}$ \\
\hline 14 & 2 & Understand how to take medications, including quantity and times. & $81.52 \pm 21.47$ \\
\hline 9 & 1 & Understand health care responsibilities. & $75.42 \pm 24.94$ \\
\hline 5 & 1 & Understand how to manage health. & $73.23 \pm 28.23$ \\
\hline 13 & 2 & Understand medications' purpose. & $73.23 \pm 27.48$ \\
\hline 4 & 1 & Had information needed for self-cafe. & $72.25 \pm 28.31$ \\
\hline 6 & 1 & Understand warning signs and symptoms. & $71.04 \pm 28.35$ \\
\hline 1 & 3 & Agreed with the health care team on health goals and means. & $70.87 \pm 24.20$ \\
\hline 7 & 4 & Had a written care plan. & $70.49 \pm 27.44$ \\
\hline 10 & 1 & Confident knew what to do to manage care. & $68.87 \pm 29.56$ \\
\hline 12 & 4 & Had a written list of appointments or exams for the next weeks. & $68.71 \pm 33.27$ \\
\hline 8 & 1 & Understand what makes the health condition better or worse. & $67.86 \pm 30.07$ \\
\hline 2 & 3 & Preferences considered when deciding health needs. & $67.34 \pm 27.34$ \\
\hline 3 & 3 & $\begin{array}{l}\text { Preferences considered when deciding where health needs are } \\
\text { met. }\end{array}$ & $67.01 \pm 29.81$ \\
\hline 11 & 1 & Confident could do what needed to take care of health. & $66.16 \pm 28.34$ \\
\hline 15 & 2 & Understand medications' side effects. & $50.09 \pm 37.60$ \\
\hline
\end{tabular}

Source: Research data, 2015. 
The distribution of the participants' answers with simple and relative frequency is also presented in each item of the instrument (Table 3). This analysis provides a better understanding of the items that had the highest agreement (grouping "agree" and "strongly agree" options) or disagreement (sum of the "disagree" and "strongly disagree" options).

Table 3 - Simple and relative frequency distribution of response options per CTM-15 Item. Porto Alegre, RS, Brazil, 2015

\begin{tabular}{|c|c|c|c|c|c|}
\hline Item & $\begin{array}{l}\text { Strongly } \\
\text { Disagree }\end{array}$ & Disagree & Agree & Strongly Agree & $\begin{array}{c}\text { Don't know/ } \\
\text { Not applicable }\end{array}$ \\
\hline 1 & $8(4.0 \%)$ & $17(8.6 \%)$ & 115 (58.1\%) & $58(29.3 \%)$ & $0(0.0 \%)$ \\
\hline 2 & $12(6.1 \%)$ & $28(14.1 \%)$ & 101 (51.0\%) & $56(28.3 \%)$ & $1(0.5 \%)$ \\
\hline 3 & 19 (9.6\%) & $20(10.1 \%)$ & 97 (49.0\%) & 60 (30.3\%) & $2(1.0 \%)$ \\
\hline 4 & $12(6.1 \%)$ & $21(10.6 \%)$ & $86(43.4 \%)$ & $78(39.4 \%)$ & $1(0.5 \%)$ \\
\hline 5 & $11(5.6 \%)$ & $22(11.1 \%)$ & $82(41.4 \%)$ & $83(41.9 \%)$ & $0(0.0 \%)$ \\
\hline 6 & $13(6.6 \%)$ & $21(10.6 \%)$ & $91(46.0 \%)$ & $73(36.9 \%)$ & $0(0.0 \%)$ \\
\hline 7 & $11(5.6 \%)$ & $22(11.1 \%)$ & $93(47.0 \%)$ & $66(33.3 \%)$ & $6(3.0 \%)$ \\
\hline 8 & $17(8.6 \%)$ & $25(12.6 \%)$ & $88(44.4 \%)$ & $66(33.3 \%)$ & $2(1.0 \%)$ \\
\hline 9 & $8(4.0 \%)$ & $12(6.1 \%)$ & $98(49.5 \%)$ & $80(40.4 \%)$ & $0(0.0 \%)$ \\
\hline 10 & $16(8.1 \%)$ & $23(11.6 \%)$ & $90(45.5 \%)$ & $68(34.3 \%)$ & $1(0.5 \%)$ \\
\hline 11 & $12(6.1 \%)$ & $36(18.2 \%)$ & $91(46.0 \%)$ & $57(28.8 \%)$ & $2(1.0 \%)$ \\
\hline 12 & $20(10.1 \%)$ & $16(8.1 \%)$ & 61 (30.8\%) & $66(33.3 \%)$ & 35 (17.7\%) \\
\hline 13 & $12(6.1 \%)$ & $14(7.1 \%)$ & $91(46.0 \%)$ & $76(38.4 \%)$ & $5(2.5 \%)$ \\
\hline 14 & $4(2.0 \%)$ & $4(2.0 \%)$ & 87 (43.9\%) & $98(49.5 \%)$ & $5(2.5 \%)$ \\
\hline 15 & $54(27.3 \%)$ & $30(15.2 \%)$ & $64(32.3 \%)$ & $43(21.7 \%)$ & $7(3.5 \%)$ \\
\hline
\end{tabular}

Source: Research data, 2015

The items with the highest percentage of agreement were 14,9 and 1 (93.4\%, 89.9\% and $87.4 \%$, respectively), while those with the highest percentage of disagreement were 15, 11 and 8 (43.5\%, 24.3\% and 21.2\%, respectively). It can be noticed that item 12 had the highest response percentage in the neutral option of the Likert scale (17.7\%), a value much higher than the rest of the instrument items.

Table 4 shows the association and correlation between the total score and the score per factor of the CTM-15 with the independent variables of the study.

Table 4 - Association and correlation between the CTM-15 total score, score per factor and independent variables. Porto Alegre, RS, Brazil, 2015

\begin{tabular}{lccccc}
$\begin{array}{l}\text { Variables } \\
\text { Who answered }\end{array}$ & Total & Factor $\mathbf{1}$ & Factor $\mathbf{2}$ & Factor $\mathbf{3}$ & Factor $\mathbf{4}$ \\
\hline Patient & \multicolumn{5}{c}{} \\
\hline Caregiver & $68.0 \pm 19.3$ & $68.9 \pm 24.3$ & $66.8 \pm 20.6$ & $67.2 \pm 21.4$ & $68.0 \pm 27.2$ \\
\hline $\mathrm{p}^{\ddagger}$ & $71.6 \pm 20.3$ & $73.0 \pm 21.8$ & $70.5 \pm 25.0$ & $70.1 \pm 24.6$ & $69.9 \pm 26.7$ \\
\hline Gender & 0.213 & 0.229 & 0.271 & 0.385 & 0.612 \\
\hline Male & & & & & \\
\hline Female & $70.7 \pm 22.6$ & $71.6 \pm 25.9$ & $70.6 \pm 22.7$ & $68.5 \pm 26.0$ & $70.8 \pm 28.2$ \\
\hline $\mathrm{p}^{\ddagger}$ & $68.4 \pm 16.8$ & $69.7 \pm 20.9$ & $66.3 \pm 22.3$ & $68.4 \pm 19.5$ & $66.9 \pm 25.8$ \\
\hline & 0.417 & 0.570 & 0.195 & 0.976 & 0.326 \\
\hline
\end{tabular}


Table 4 - Cont.

\begin{tabular}{lccccc}
\hline Variables & Total & Factor 1 & Factor 2 & Factor 3 & Factor 4 $^{\text {Age (years old) }}{ }^{\dagger}$ \\
\hline$p^{\S}$ & -0.033 & -0.052 & -0.048 & 0.082 & -0.087 \\
\hline Schooling level $^{\dagger}$ & 0.649 & 0.469 & 0.508 & 0.252 & 0.225 \\
\hline$p^{\|}$ & -0.105 & -0.111 & -0.069 & -0.102 & 0.059 \\
\hline Risk rating $^{\dagger}$ & 0.157 & 0.132 & 0.360 & 0.170 & 0.432 \\
\hline$p^{\|}$ & 0.078 & 0.070 & 0.061 & 0.019 & 0.138 \\
\hline Length of stay (days) $^{\dagger}$ & 0.277 & 0.332 & 0.404 & 0.789 & 0.054 \\
\hline$p^{\|}$ & 0.095 & 0.098 & 0.092 & 0.093 & 0.032 \\
\hline
\end{tabular}

\section{Shift of discharge*}

\begin{tabular}{|c|c|c|c|c|c|}
\hline Morning & $63.6 \pm 17.5$ & $66.2 \pm 19.5$ & $61.3 \pm 22.5$ & $63.1 \pm 26.6$ & $59.5 \pm 27.4$ \\
\hline Afternoon & $72.0 \pm 19.7$ & $72.5 \pm 24.2$ & $70.7 \pm 21.6$ & $71.6 \pm 20.6$ & $73.5 \pm 25.3$ \\
\hline Evening & $67.6 \pm 20.5$ & $69.3 \pm 23.7$ & $68.2 \pm 24.2$ & $64.4 \pm 23.7$ & $64.4 \pm 28.7$ \\
\hline$p^{q}$ & 0.062 & 0.324 & 0.087 & 0.056 & 0.010 \\
\hline \multicolumn{6}{|l|}{ Day of discharge* } \\
\hline Weekday & $69.2 \pm 19.8$ & $70.2 \pm 23.5$ & $67.8 \pm 22.9$ & $68.6 \pm 23.2$ & $68.9 \pm 25.9$ \\
\hline Weekend & $70.5 \pm 19.4$ & $72.2 \pm 22.8$ & $70.5 \pm 20.9$ & $67.5 \pm 20.8$ & $68.4 \pm 31.2$ \\
\hline$p^{q}$ & 0.708 & 0.639 & 0.511 & 0.787 & 0.925 \\
\hline No. of previous hospital visits ${ }^{\dagger}$ & $0.147^{\ddagger}$ & $0.170^{\ddagger}$ & 0.112 & 0.089 & 0.062 \\
\hline$p^{\|}$ & 0.039 & 0.017 & 0.121 & 0.214 & 0.389 \\
\hline \multicolumn{6}{|l|}{ Emergency readmission* } \\
\hline Yes & $70.7 \pm 20.5$ & $72.7 \pm 23.1$ & $68.2 \pm 24.4$ & $68.9 \pm 23.6$ & $70.2 \pm 27.8$ \\
\hline No & $68.9 \pm 19.4$ & $69.6 \pm 23.4$ & $68.4 \pm 21.6$ & $68.2 \pm 22.4$ & $68.1 \pm 26.6$ \\
\hline $\mathrm{p}^{\ddagger}$ & 0.543 & 0.383 & 0.964 & 0.845 & 0.603 \\
\hline \multicolumn{6}{|l|}{$\begin{array}{l}\text { Hospital admission after } \\
\text { discharge from emergency } \\
\text { department* }\end{array}$} \\
\hline Yes & $74.9 \pm 17.2$ & $76.7 \pm 18.8$ & $70.4 \pm 25.6$ & $74.6 \pm 17.4$ & $77.6 \pm 19.4$ \\
\hline No & $68.3 \pm 20.1$ & $69.3 \pm 24.0$ & $67.9 \pm 21.9$ & $67.1 \pm 23.6$ & $66.9 \pm 28.0$ \\
\hline $\mathrm{p}^{\ddagger}$ & 0.072 & 0.087 & 0.564 & 0.075 & 0.032 \\
\hline
\end{tabular}

Source: Research data, 2015.

*Values expressed as mean value \pm standard deviation. †Values expressed as correlation coefficient. fUsing Student's t-test. §Using Pearson's correlation test. ||Using Spearman's correlation test. qUsing the analysis of variance (ANOVA) test complemented by Tukey.

The total CTM-15 score was higher among caregivers, men and patients discharged in the afternoon shift but without statistical difference. It is noteworthy that the mean score was higher in patients readmitted to the emergency department or who were hospitalized after discharge from the emergency department, although this is not a significant difference.
There was a statistically significant association between the score of Factor 4 (Care Plan) and the variables "shift of discharge" and "hospital admission after discharge from the emergency department". In the correlation between the total score and Factor 1 (Management Preparation) with the variable "number of previous hospital visits", positive correlations of low magnitude were observed. The CTM-15 
mean value increased as the number of prior emergency care visits increased. Other associations and correlations were not significant.

\section{DISCUSSION}

The results of this study made it possible to evaluate the quality of the care transition at discharge from the emergency department of patients with chronic non-communicable diseases. The mean CTM-15 score in this study (69.5 \pm 19.7$)$ was almost satisfactory, indicating a moderate quality.

Studies that used CTM-15 or CTM-3 (a simplified version of the instrument) to evaluate care transition have shown high scores, indicating a positive quality in the patients' perception ${ }^{(15-16)}$. There is a tendency for participants to answer questions in the affirmative ${ }^{(15,17)}$, producing positive results that perhaps are distorted and do not represent the true quality of the care transition ${ }^{(18)}$. Therefore, it is recommended that the CTM be used with caution and associated with other quality of care indicators ${ }^{(17-18)}$.

However, the mean score obtained in this study was lower than that found in a research conducted in emergency services in the United States ${ }^{(6)}$ and in international investigations in inpatient wards ${ }^{(10-11)}$. Within the Brazilian context, CTM-15 was used with hospitalized patients with clinical problems, identifying a higher average score $(79.0 \pm 15.3)^{(13)}$.

The quality of care transition in emergency departments is expected to be lower than in inpatient units due to the accelerated pace of care and the shorter length of stay ${ }^{(5)}$. The literature indicates a positive association between patient satisfaction, care transition and length of stay ${ }^{(15)}$. In addition, it is assumed that the professionals' conception of the purpose of their work in emergencies is related to the care of patients with life-threatening conditions, so that perhaps, after clinical stabilization, the patient's transition to home would not be a priority of these services. On the other hand, professionals from inpatient units have more opportunities to prepare the patient for discharge, but also believe that this is part of their work.

By assessing the individual score and the score per factor of the CTM-15 in this study, as well as the percentages of disagreement of the items, it was found that the main gaps in the care transition of patients with CNCDs upon discharge from the emergency department were the following: understanding medications use and side effects; confidence in self-management after discharge; understanding of the health condition and of the aggravating and attenuating factors; and incorporating patient and caregiver preferences into the post-discharge care plan. Furthermore, data indicate that many patients left the emergency department without remembering, knowing or having referrals and scheduling for post-discharge follow-up. Similar difficulties have been described in the literature ${ }^{(16)}$, demonstrating that the problems are convergent in different health services and systems. Thus, it can be verified that interventions are needed to improve discharge practices, the patient's understanding of post-discharge care, and the inclusion of patient preferences in decision making ${ }^{(18)}$.

It is understood that discharge planning and the design of a care plan are essential to ensure the patient is prepared for self-management at home. When discharge is planned, during hospitalization, the multi-professional team checks the patient's understanding of their health, combines new and pre-hospitalization medications, sets treatment goals with patient preferences, and schedules hospital stay ${ }^{(3,9)}$. The nurse can act as a care coordinator ${ }^{(9)}$, identifying the needs and preferences of the patient and their family, creating an individualized plan and developing health education actions during hospitalization, which may contribute to a reduction in hospital readmissions.

In this study, it was verified that the Management Preparation factor obtained the highest score, with items 9 (Understand health care responsibilities) and 5 (Understand how to manage health) having good mean values while item 11 (Confident could do what needed to take care of health) had the second lowest score. The short time available to prepare the patient and family members, added to the accumulation of information, can influence the understanding of the orientations and the clarification of doubts, which may lead to uncertainties and lack of confidence in the post-discharge care. Discharge planning and health education actions could contribute to this aspect ${ }^{(7)}$.

Considering the specificities of emergency departments and nursing work, the use of protocols based on the systematization of nursing care for discharge planning can help the health education process for patients with chronic diseases. Other methods of health education are described in the literature ${ }^{(7,9)}$ and may be used with patients in emergency services.

Prior scheduling of follow-up appointments, articulation with health services, and post-discharge follow-up are important strategies for qualifying patient transitions ${ }^{(3,9)}$. However, the lack of referrals and of articulation of emergency departments with other care network services was also evidenced in another study ${ }^{(4)}$. The adoption of "liaison nurses" as coordinators of the care transition process can improve integration between services, promote continuity of care and decrease return to acute care ${ }^{(19)}$.

Regarding readmission to the emergency department, the percentage of patients who sought emergency care after discharge was much higher than the one obtained in 
other studies. While in this survey it was found that about $40 \%$ of the patients were readmitted to the service, values of $3.5 \%$ were found in a survey conducted in China ${ }^{(20)}$, and $17 \%$ in the United States ${ }^{(17)}$. Similarly, with respect to hospital readmission, the percentage was higher than that found in the studies ${ }^{(17,20)}$. However, unlike what is described in the literature ${ }^{(10,17)}$, there was no association between the quality of care transition (total CTM-15 score) and readmission.

In an investigation with patients in a US emergency department, it was found that a 10-point increase in the CTM score, representing a better transition experience, was associated with a $12 \%$ increase in the risk of readmission in the service. Also, people with Medicaid insurance (for low-income individuals), descendants of Native Americans and with a poorer self-reported health condition were found to have lower scores ${ }^{(6)}$. In this study, the total CTM-15 score only correlated with the "number of previous hospital visits" variable, which indicates that patients with previous hospitalizations had a better quality of care transition. Perhaps health professionals perform more transitional actions when the patient is readmitted to the service.

The data from this research suggests that the quality of care transition for patients in emergency care was little influenced by patient-related factors, and may be more affected by health care practices and health policies at the institutional and national levels.

It can be noticed that the CTM-15 Cronbach's alpha coefficient was satisfactory, indicating good internal consistency of the instrument, a result similar to that found in other studies conducted in the United States ${ }^{(17)}$, China ${ }^{(20)}$ and Brazil ${ }^{(13)}$.

\section{- CONCLUSION}

It was found that the quality of care transition for patients with non-communicable diseases discharged from the emergency department was moderate. Aspects related to orientation for self-management had positive results. However, the main gaps identified included understanding of medication use and side effects, confidence in the necessary care after discharge, understanding the health condition and its aggravating and mitigating factors, incorporating patient and caregiver preferences into the care plan for after discharge and referral for post-discharge follow-up. The total CTM-15 score had a small positive correlation with the number of previous hospital visits factor and was not associated with the other demographic and clinical variables investigated.

The contribution of the study to nursing is highlighted, playing a fundamental role in the care transition, identifying aspects that need to be improved in management and care practices. It is necessary to strengthen the role of nurses in coordinating the care transition, participating in discharge planning, providing self-management guidance in health, as well as assisting in the articulation between hospital and primary care services. Thus, other investigations need to be carried out to give visibility to the theme and to support changes and qualification of practices.

The limitations of this investigation include the participation of caregivers as substitute respondents, the potential communication challenge in data collection by phone and the difficulty of comparing and discussing the results with national studies. This study is expected to spark a debate on the transitional care in the country.

\section{口 REFERENCES}

1. Utzumi FC, Lacerda MR, Bernardino E, Gomes IM, Aued GK, Sousa SM. Continuity of care and the symbolic interactionism: a possible understanding. Texto Contexto Enferm. 2018;27(2):e4250016. doi: https://doi.org/10.1590/0104070720180004250016

2. Malta DC, Bernal RTI, Lima MG, Araújo SSC, Silva MMA, Freitas MIF, et al. Noncommunicable diseases and the use of health services: analysis of the National Health Survey in Brazil. Rev Saúde Pública. 2017;51(Suppl 1):4s. doi: https://doi.org/10.1590/s1518-8787.2017051000090

3. Hirschman KB, Shaid E, McCauley K, Pauly MV, Naylor MD. Continuity of care: the Transitional Care Model. Online J Issues Nurs. 2015 [cited 2019 Apr 29];20(3):1. Available from: http://ojin.nursingworld.org/MainMenuCategories/ ANAMarketplace/ANAPeriodicals/0JIN/TableofContents/Vol-20-2015/No3Sept-2015/Continuity-of-Care-Transitional-Care-Model.html

4. Acosta AM, Lima MADS. Frequent users of emergency services: associated factors and reasons for seeking care. Rev Latino-Am Enfermagem. 2015;23(2):337-44. doi: https://doi.org/10.1590/0104-1169.0072.2560

5. Mäkinen M, Castrén M, Huttunen K, Sundell S, Kaartinen J, Ben-Meir M, et al. Assessing the discharge instructing in the emergency department: patient perspective. Int Emerg Nurs. 2019;43:40-4. doi: https://doi.org/10.1016/j. ienj.2018.07.005

6. Sabbatini AK, Gallahue F, Newson J, White S, Gallagher T. Capturing emergency department discharge quality with the care transitions measure: a pilot study. Acad Emerg Med. 2019;26(6):605-9. doi: https://doi.org/10.1111/acem.13623

7. Lima MADS, Magalhães AMM, Oelke ND, Marques GQ, Lorenzini E, Weber LAF et al. Care transition strategies in Latin American countries: an integrative review. Rev Gaúcha Enferm. 2018;39:e20180119. doi: https://doi.org/10.1590/19831447.2018.20180119

8. Jeffs L, Kuluski K, Law M, Saragosa M, Espin S, Ferris E, et al. Identifying effective nurse-led care transition interventions for older adults with complex needs using a structured expert panel. Worldviews Evid Based Nurs. 2017;14(2):13644. doi: https://doi.org/10.1111/wvn. 12196

9. Weber, LAF, Lima, MADS, Acosta AM, Marques GQ. Care transition from hospital to home: integrative review. Cogitare Enferm. 2017;22(3):e47615. doi: https:// doi.org/10.5380/ce.v22i3.47615

10. Goldstein JN, Hicks LS, Kolm P, Weintraub WS, Elliott DJ. Is the care transitions measure associated with readmission risk? analysis from a single academic center. J Gen Intern Med. 2016 [cited 2019 Apr 08];31(7):732-8. Available from: https://www.ncbi.nlm.nih.gov/pmc/articles/PMC4907944/ 
11. Chan B, Goldman LE, Sarkar U, Schneidermann M, Kessell E, Guzman D, et al. The effect of a care transition intervention on the patient experience of older multi-lingual adults in the safety net: results of a randomized controlled trial. J Gen Intern Med. [Internet]. 2015 [cited 2019 Apr 08];30(12):1788-94. Available from: https://www.ncbi.nlm.nih.gov/pmc/articles/PMC4636586/

12. Acosta AM. Transição do cuidado de pacientes com doenças crônicas: do serviço de emergência para o domicílio [tese]. Porto Alegre (RS): Universidade Federal do Rio Grande do Sul; 2016 [cited 2019 Apr 10]. Available from: https://www.lume.ufrgs.br/bitstream/handle/10183/152735/001009949. pdf? sequence $=1 \&$ isAllowed $=y$

13. Acosta AM, Lima MADS, Marques GQ, Levandovski PF, Weber LAF. Brazilian version of the Care Transitions Measure: translation and validation. Int Nurs Rev. 2017;64(3):379-87. doi: https://doi.org/10.1111/inr.12326

14. Coleman EA, Mahoney E, Parry C. Assessing the quality of preparation for posthospital care from the patient's perspective: the Care Transitions Measure. Med Care. 2005;43(3):246-55. doi: https://doi.org/10.1097/00005650200503000-00007

15. Berenguer-García N, Roldán-Chicano MT, Rodríguez-Tello J, García-López MM, Dávila-Martínez R, Bueno-García MJ. Validación del cuestionario CTM3-modificado sobre satisfacción con la continuidad de cuidados: un estudio de cohortes. Aquichan. 2018 [cited 2019 Apr 08];18(1):9-19. Available from: http://aquichan.unisabana.edu.co/index.php/aquichan/article/view/6967

16. Ford BK, Ingersoll-Dayton B, Burgio K. Care transition experiences of older veterans and their caregivers. Health Soc Work. 2016 [cited 2019 Apr 06];41(2):129-38. Available from: https://www.ncbi.nlm.nih.gov/pmc/ articles/PMC4888094/
17. Anatchkova MD, Barysauskas CM, Kinney RL, Kiefe Cl, Ash AS, Lombardini L, et al. Psychometric evaluation of the Care Transition Measure in TRACE-CORE: do we need a better measure? J Am Heart Assoc. 2014;3(3):e001053. doi: https:// doi.org/10.1161/JAHA.114.001053

18. Horwitz LI, Moriarty JP, Chen C, Fogerty RL, Brewster UC, Kanade S, et al. Quality of discharge practices and patient understanding at an academic medical center. JAMA Intern Med. 2013;173(18):1715-22. doi: https://doi.org/10.1001/ jamainternmed.2013.9318

19. Ribas EN, Bernardino E, Larocca LM, Poli Neto P, Aued GK, Silva CPC. Nurse liaison: a strategy for counter-referral. Rev Bras Enferm. 2018;71(Suppl 1):54653. doi: https://doi.org/10.1590/0034-7167-2017-0490

20. Cao X, Chen L, Diao Y, Lang T, Wenjie L, Xiaolian J. Validity and reliability of the Chinese version of the care transition measure. PLoS One. 2015;10(5):e0127403. doi: https://doi.org/10.1371/journal.pone.0127403

\section{Acknowledgments:}

To the Coordination for Improvement of Higher Education Personnel (Coordenação de Aperfeiçoamento de Pessoal de Nivel Superior, (APES) for granting a doctoral scholarship to Aline Marques Acosta, and to the National Council for Scientific and Technological Development (Conselho Nacional de Desenvolvimento Cientifico e Tecnológico, (NPq) for Research Aid, Process No. 478640/2012-9.

\section{- Corresponding author:}

Aline Marques Acosta

E-mail: aline.acosta@gmail.com

\section{Associate editors:}

Ana Karina Silva da Rocha Tanaka

Cecília Helena Glanzner

Received: 04.29.2019

Approved: 08.27.2019

\section{Editor-in-chief:}

Maria da Graça Oliveira Crossetti 